\title{
Effect of Jasmonic Acid on Photosynthetic Pigments and Stress Markers in Cajanus cajan (L.) Millsp. Seedlings under Copper Stress
}

\author{
Sharma Poonam, Harpreet Kaur, Sirhindi Geetika* \\ Department of Botany, Punjabi University, Patiala, India. \\ Email: "geetikasir123@gmail.com \\ Received February 22 ${ }^{\text {nd }}, 2013$; revised March $25^{\text {th }}, 2013$; accepted April $2^{\text {nd }}, 2013$
}

Copyright (C) 2013 Sharma Poonam, Sirhindi Geetika. This is an open access article distributed under the Creative Commons Attribution License, which permits unrestricted use, distribution, and reproduction in any medium, provided the original work is properly cited.

\begin{abstract}
Jasmonates are class of plant growth regulators act as signal molecule that intercede various components in physiological and metabolic regulation, stress responses and possibly communication through signal transduction. Oxidative stress due to heavy metal exposure stimulates synthesis and activity of antioxidant metabolites and enhances antioxidant enzyme activities that could protect plant tissues. The aim of this study was to investigate the exogenous effect of JA at seed level which can transduce throughout seedling growth and regulate antioxidant activities such as superoxide dismutase (SOD; EC 1.15.1.1) and guaiacol peroxidase (POD; EC 1.11.1.7) in 12 days old seedlings of pigeon pea ( $\mathrm{Ca}$ janus cajan (L.) Millsp.) in presence and/or absence of copper. The activity of SOD and POD increased significantly in presence of $\mathrm{Cu}^{2+}$ after seed priming with JA. JA also helps in chlorophyll and carotenoid accumulation and neutralizes the toxic effect of $\mathrm{Cu}^{2+}$ on seedlings. This is the first report of JA effect on photosynthetic pigment accumulation and $\mathrm{H}_{2} \mathrm{O}_{2}$ mitigating enzymes i.e. SOD and POD and it could be recommended that seed priming with JA help in ameliorating toxic effect of $\mathrm{Cu}^{2+}$.
\end{abstract}

Keywords: Jasmonic Acid; Copper Sulphate; Lipid Peroxidation; Superoxide Dismutase; Guaiacol Peroxidase; Total Chlorophyll; Carotenoids

\section{Introduction}

Jasmonic acid is a member of plant growth regulators named jasmonates occurring ubiquitously in plants which exhibit hormone like properties, regulating various physiological processes related to plant growth and development, promotion of leaf senescence estimated by decrease in chlorophyll content and depression of photosynthesis related gene which was one of the first reported physiological effects of jasmonates group [1]. But these consequences are based mainly on the studies done on excised or intact differentiated leaves after exogenous application of jasmonates [2]. Till now it is considered that jasmonates particularly methyl esters of JA (Me-JA) as a chemical stress agent mimicking the effect of that appear in response to external stress factors inducing senescence [3]. Me-JA preferentially inhibited chlorophyll accumulation at the level of chlorophyll precursors

\footnotetext{
"Corresponding author.
}

in the dark as compared to other inhibitory growth regulators as chemicals [4] under different environmental conditions.

Heavy metal is one of the common stress, plants have from their habitat without any option. Accumulation of heavy metals in plants when passes the threshold level, resulted to toxicity in plants lead to many morphological and physiological changes [5]. Copper is a heavy metal which is an essential ion for various proteins which are structural and functional part of vital machinery of plant cell. The requirement of $\mathrm{Cu}^{2+}$ ion by the plant is very low, as core component of photosynthetic pigments and as antioxidant enzymes such as SOD. Unfortunately, plants find an ample supply of copper through their roots from soil and accumulated in system causing stress [6] along with triggering of certain physiological responses [7].

Cajanus cajan (L.) Millsp. (pigeonpea) is an important pulse crop of the world which is rich in protein. Pigeonpea is major food legume of India and has great area un- 
der cultivation, but still the productivity is at very low level and number of endogenous and exogenous factors is responsible for this low yield. Soil pollution and that too heavy metal toxicity is one of the major factors responsible for this low yield. In present study we analysed the effect of Jasmonic acid and $\mathrm{Cu}^{2+}$ on photosynthetic pigments and stress markers in seedlings of $C$. cajan growing under copper treatment after priming the seeds with micro-, nano- and pico-molar concentration of JA. We also studied the synergistic effect of $\mathrm{JA}$ and $\mathrm{Cu}^{2+}$ on various stress markers and accumulation of photosynthetic pigments with equimolar solution of each.

\section{Material and Methods}

\subsection{Chemicals}

Jasmonic acid was obtained from Sigma-Aldrich Chemicals Pvt Ltd, INDIA. Chemicals and reagents used for various biochemical analyses were purchased from Merck. The experiments were performed under controlled conditions in seed germinator.

\subsection{Collection of Seeds and Experimental Setup}

Seeds of Cajanus cajan AL-201 (certified) were procured from Department of Plant Breeding, Punjab Agriculture University, Ludhiana, India. Healthy seeds were manually selected and treated with $5 \%$ hypochlorite (v/v) for 5 minutes and then washed for 30 minutes in free flowing tap water followed by 4 - 5 times washing with deionised water. Seed priming was done to surface sterilized seeds with different concentrations of JA $(1 \mu \mathrm{M}, 1$ $\mathrm{nM}$, and $1 \mathrm{pM}$ ) and DW as control, for 6 hours. JA treated and untreated seeds were sowed in petriplate in absence and/or presence of $\mathrm{Cu}^{2+}$ in triplicate. $10 \mathrm{~mL}$ of 5 $\mathrm{mM}$ copper sulphate was given on zero and sixth day in petriplate where they are required and DW taking as control. Treated and untreated seeds were grown for 12 days under controlled conditions of seed germinator, observing $24^{\circ} \mathrm{C}$ temperatures, 16/8 hours dark and light period and light intensity fall uniformly on each petriplate at 200 PAR while humidity was set at $80 \%$. Present study was conducted to see the effect of JA, if any at seed level in protecting the photosynthetic pigments and regulating antioxidant enzymes in mitigating the toxic effect of copper on seedling growth.

\subsection{Treatment of JA and Copper}

Our experiment consisted of 8 treatments with 3 replication of each treatment. The treatment included Jasmonic acid $(0,1 \mu \mathrm{M}, 1 \mathrm{nM}, 1 \mathrm{pM})$ and $\mathrm{Cu}^{2+}(0,5 \mathrm{mM})$ and combination of Jasmonic acid and $\mathrm{Cu}^{2+}(1 \mu \mathrm{M}+5 \mathrm{mM}, 1$ $\mathrm{nM}+5 \mathrm{mM}$ and $1 \mathrm{pM}+5 \mathrm{mM})$. The growth parameters in terms of root and shoot length were examined after 12 days after sowing (DAS) of exposure to continuous solution of copper.

\subsection{Determination of Total Chlorophyll and Carotenoid Content}

$100 \mathrm{mg}$ fresh shoot tissue was homogenized in $80 \%$ chilled acetone using pre-chilled pestle and mortar. Homogenate was centrifuged and supernatant was used for chlorophyll and carotenoid estimation using UV-visible spectrophotometer of mini 1240 (Shimadzu, Japan) [8].

\subsection{Estimation of MDA and Proline Content}

MDA and proline content was determined using colorimetric method. The level of MDA was measured by Thiobarbituric acid reaction method [9]. Proline estimation was done following method of Bates et al. [10]. The plant material was homogenized with $3 \%$ sulpho-Salicylic acid. The homogenate was filtered and glacial acetic acid and acid-ninhydrin was added to the supernatant. After shaking for 1 minute, the reaction mixture was incubated at $100^{\circ} \mathrm{C}$ for $1 \mathrm{~h}$. Reaction was stopped by adding toluene and absorbance was taken at $520 \mathrm{~nm}$ using spectrophotometer.

\subsection{Preparation of Enzyme Extract}

One gram of shoot tissue of Cajanus cajan were homogenized in $3 \mathrm{ml}$ of pre-chilled phosphate buffer, $(\mathrm{pH}$ 7.2 ) in chilled pestle and mortar. The homogenates were centrifuged at $15,000 \mathrm{rpm}$ for 15 minute at $4^{\circ} \mathrm{C}$ and supernatant collected and used for enzyme activities of SOD and POD along with total proteins.

\subsection{Determination of Total Proteins}

Total proteins were estimated by the method of Lowry et al. [11]. One $\mathrm{ml}$ of enzyme extract was kept in $1 \mathrm{ml}$ of ice cold $20 \%$ TCA for 18 hours. Homogenate was centrifuged and pellet was dissolved in $0.1 \mathrm{~N} \mathrm{NaOH}$ for protein estimation. The absorbance was measured at 750 $\mathrm{nM}$.

\subsection{Superoxide Dismutase Activity (EC 1.15.1.1)}

The assay of superoxide dismutase was carried out based on the reduction of nitro blue tetrazolium (NBT) [12]. To $0.5 \mathrm{ml}$ of enzyme extract, $1.8 \mu \mathrm{l}$ of $50 \mathrm{mM}$ of Sodium Carbonate buffer (pH 10), $750 \mu \mathrm{l}$ of $96 \mu \mathrm{M}$ NBT and 150 $\mu 1$ Triton X-100 were added. The reaction was initiated by adding $0.4 \mathrm{ml}$ of $1 \mathrm{mM}$ hydroxylamine hydrochloride. Absorbance was taken at $540 \mathrm{~nm}$ using spectrophotometer mentioned elsewhere, and activity of SOD was taken as an increase in absorbance for $2 \mathrm{~min}$ at $25^{\circ} \mathrm{C}$. The con- 
trol was simultaneously run without enzyme extract. Units of SOD were expressed as amount of enzyme required for inhibiting the reduction of NBT by $50 \%$. The specific activity was expressed in terms of Units $\mathrm{mg}^{-1}$ of protein.

\subsection{Activity of Guaiacol Peroxidase} (EC 1.11.1.7)

Guaiacol peroxidase was assayed by mixing $50 \mu 1$ of Guaiacol, $30 \mu \mathrm{l}$ of $\mathrm{H}_{2} \mathrm{O}_{2}$ and $3 \mathrm{ml}$ of potassium phosphate buffer and enzyme extract. Blank was prepared by adding all the reagents except enzyme extract [13].

\section{Statistical Analysis}

All analysis was done on a completely randomized design. All data obtained was subjected to unpaired t-test. Each data was the mean of three replicates $(n=3)$ except for shoot and root length where $\mathrm{n}=5$ and comparisons of $\mathrm{p}$-values $<0.05$ were considered significant and different from control.

\section{Results and Discussions}

\subsection{Effect of JA and Copper on Growth}

Jasmonic acid treated seeds showed $22 \%$ increase in seed germination rate as compared to control while in presence of copper 3\% decrease in germination rate was observed from that of control seeds. Interestingly seeds grown in presence of $\mathrm{Cu}^{2+}$ after treated with $1 \mu \mathrm{M} \mathrm{JA}$ showed $20 \%$ decrease in germination rate as compared to control distilled water seeds, imitate the stress properties of $\mathrm{Cu}^{2+}$. On the other hand $1 \mathrm{nM}$ and $1 \mathrm{pM} \mathrm{JA}$ showed augmented effect on seed germination in presence of $\mathrm{Cu}^{2+}$ showing $7 \%$ and $14 \%$ increase in germination rate as compared to control distilled water seeds (Table 1).

Table 1. Effect of JA on different growth parameters of Cajanus cajan grown under copper.

\begin{tabular}{cccc}
\hline Treatment & $\begin{array}{c}\text { Germination } \\
(\%)\end{array}$ & $\begin{array}{c}\text { Root length } \\
(\mathrm{cm})\end{array}$ & $\begin{array}{c}\text { Shoot length } \\
(\mathrm{cm})\end{array}$ \\
\hline $\mathrm{CN}$ & 82 & $5.8 \pm 0.10$ & $7.03 \pm 1.53$ \\
$\mathrm{Cu}$ & 80 & $1.46 \pm 0.45^{*}$ & $4.7 \pm 1.06$ \\
$1 \mu \mathrm{M} \mathrm{JA}$ & 99 & $6.06 \pm 0.51$ & $5.63 \pm 0.66$ \\
$1 \mu \mathrm{M} \mathrm{JA}+\mathrm{Cu}$ & 66 & $1.33 \pm 0.15^{*}$ & $5.16 \pm 0.60$ \\
$1 \mathrm{nM} \mathrm{JA}$ & 99 & $4.3 \pm 0.72^{*}$ & $4.13 \pm 0.77^{*}$ \\
$1 \mathrm{nM} \mathrm{JA}+\mathrm{Cu}$ & 88 & $2.0 \pm 0.86^{*}$ & $3.86 \pm 0.40^{*}$ \\
$1 \mathrm{pM} \mathrm{JA}$ & 90 & $6.93 \pm 0.15^{*}$ & $4.43 \pm 0.81$ \\
$1 \mathrm{pM} \mathrm{JA}+\mathrm{Cu}$ & 94 & $3.36 \pm 1.19^{*}$ & $3.1 \pm 0.52^{*}$ \\
\hline
\end{tabular}

Lower concentration of JA as seed priming treatment in presence of $\mathrm{Cu}^{2+} / \mu \mathrm{M}$ neutralize damaging effect of copper by operating in antagonist way. Seedling growth in terms of root and shoot length also showed synergistic mechanism of negative effect on growth particularly on shoot length. Root length also affected negatively in presence of JA alone or with equimolar solution of copper. One interesting observation found in present study was that micro and picomolar JA treatments positively affected root length to $5 \%$ and $20 \%$ respectively, as compared to control untreated seedlings. Overall JA showed stronger inhibitory effect on seedling growth in presence or absence of copper.

\subsection{Determination of Total Chlorophyll and Carotenoid Content}

All the reports related to jasmonates effect on photosynthetic pigments available till date mentioned JA and its methyl ester as an inhibitor for chlorophyll and carotenoid synthesis and accumulation in growing seedlings. Exposure of JA in presence or absence of copper shows antagonist effect on total chlorophyll (Figure 1(a)) and carotenoid (Figure 1(b)) accumulation in 12 days old seedlings. In seedlings treated with JA alone, chlorophyll and carotenoid accumulation increased with increase in JA concentration from pico- $(4.58 \%)$ to nano- $(64.71 \%)$ to micro-molar $(92.72 \%)$. But when JA primed seeds grown in presence of copper solution the trend became opposite in terms of chlorophyll and carotenoid accumulation i.e. with increase in concentration of JA pigment accumulation decreased. But overall in present study JA treatment has positive significant effect on pigment accumulation in absence or presence of $\mathrm{Cu}^{2+}$ although the trend shows the antagonism. The results presented here are completely antagonistic to earlier reports which showed that exogenous application of Me-JA in excised cotyledons of Cucurbita pepo preferentially inhibited accumulation of chlorophyll and when applied in a mixture of cytokinin and Me-JA, neutralization of stimulatory effect of cytokinin on chlorophyll accumulation [4]. The positive effect of copper on chlorophyll and carotenoid accumulation is further strongly enhanced in presence of JA. Drought stress significantly increased photosynthetic pigments in sweet basil which is ameliorated further by JA treatment [14]. The stronger overall stimulatory effect of JA on photosynthetic pigment accumulation could be due to its stronger effect on the chlorophyll synthesis pathway specially $\delta$-ALA (aminolevulinic acid) which is the rate limiting step in the biosynthesis of chlorophyll during earliest stages of greening [15]. JA treatment resulted in an increase of active cytokinin concentration which enhances chlorophyll accumulation in 


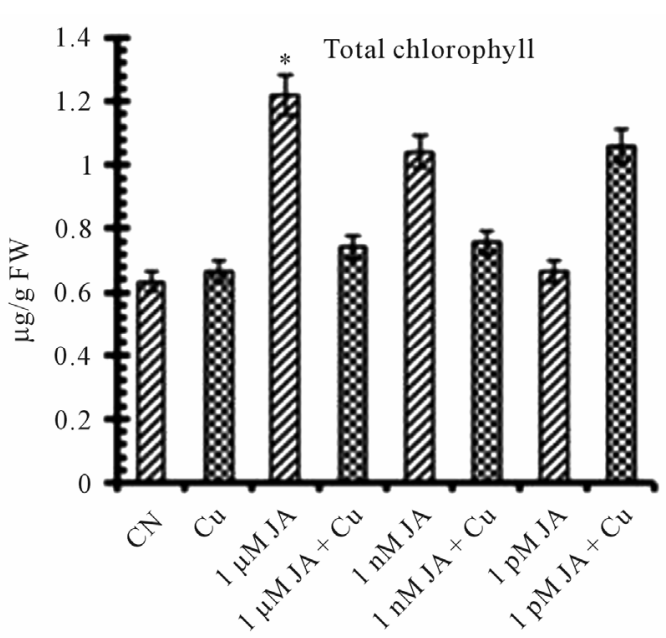

Treatments

(a)

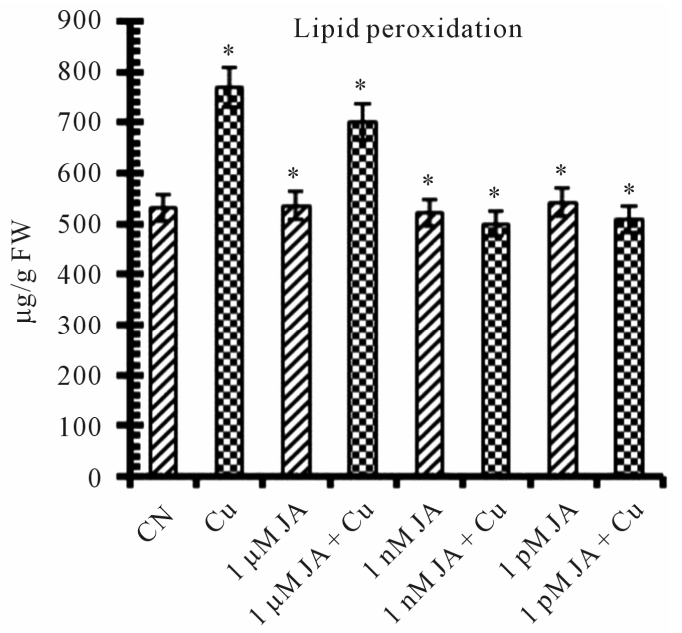

Treatments

(c)

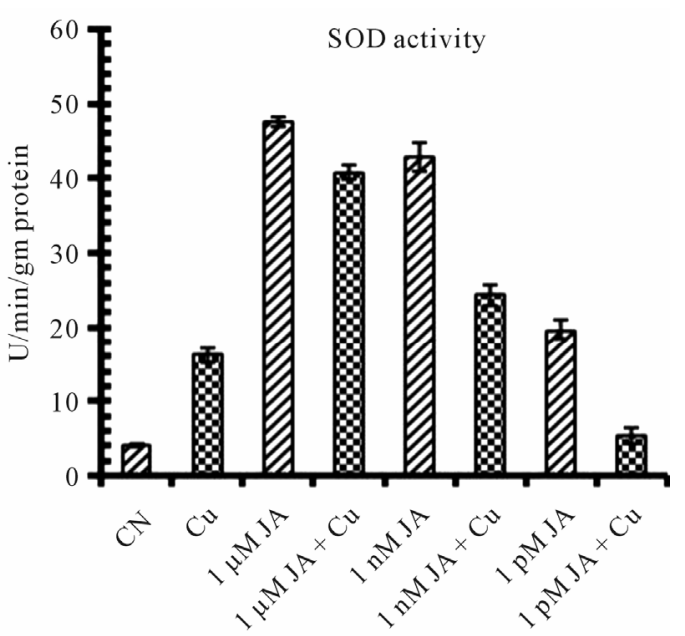

Treatments

(e)

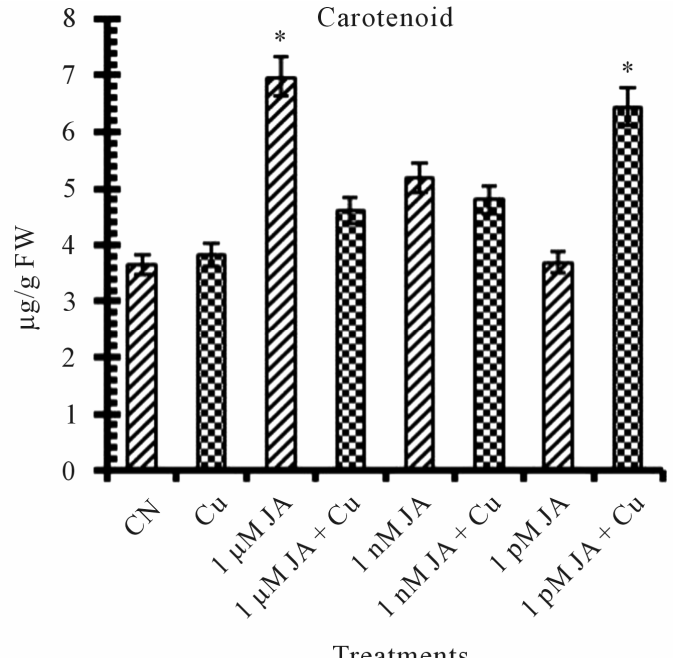

(b)

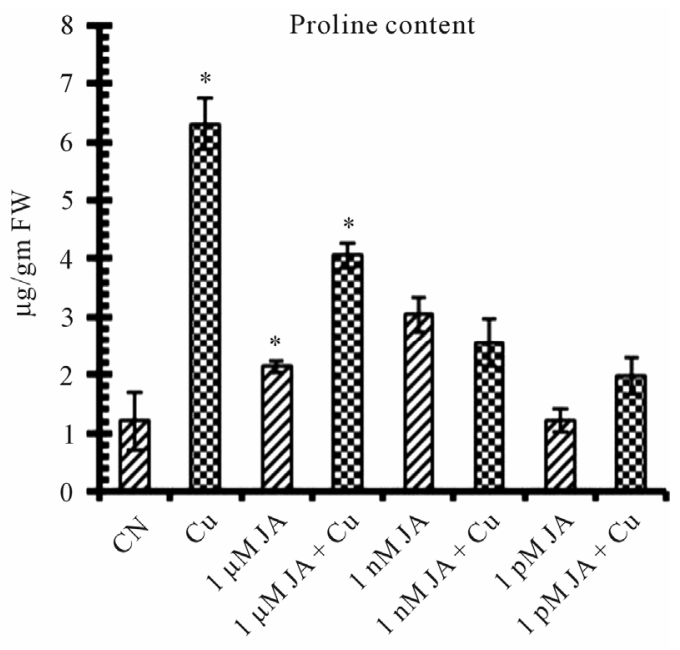

Treatments

(d)



Treatments

(f) 


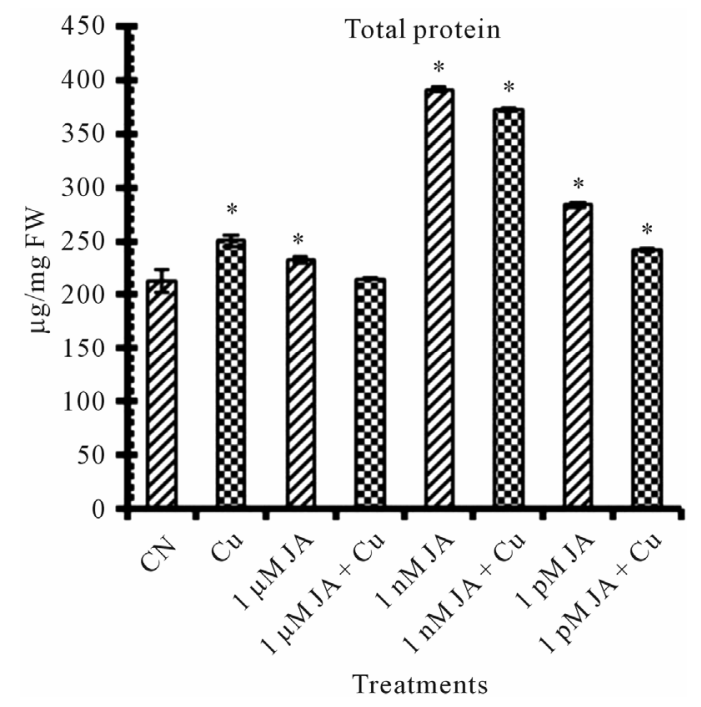

(g)

Figure 1. Levels of biochemical and antioxidant enzymes of Cajanus cajan in presence/absence of $\mathrm{JA}$ and $\mathrm{Cu}^{2+}$. (a) Total chlorophyll; (b) Carotenoids; (c) Lipid peroxidation; (d) Proline; (e) SOD activity; (f) POD activity; (g) Total protein (values represent average of triplicates and expressed as mean \pm SD).

potato plant [16]. Cytokinin treatment enhanced the amount of $\delta$-ALA accumulation in Cucurbita pepo [4]. Cytokinin is the phytohormones promoting light harvesting potential capacity of the plant, thus exerting a co-operative effect on the process of greening [17-19]. It is reasonable to assume that the JA treatment may increase cytokinin concentration which enhanced $\delta$-ALA either at synthesis level or at its activity level but further investigation is needed to prove that.

\subsection{Estimation of MDA and Proline Content}

There are number of factors, plants showed at morphological and biochemical level which can be taken as stress indicators under inadequate environmental conditions. Lipid peroxidation (MDA) increases in presence of copper Figure 1(c) environment indicated that $5 \mathrm{mM}$ $\mathrm{Cu}^{2+}$ is lethal and responsible for disintegration of plasma membrane and thus caused decrease in growth of cell. In present study $45 \%$ of lipid peroxidation increase was observed in presence of $\mathrm{Cu}^{2+}$. JA increases lipid peroxidation that was harmful to the cells [20]. 1 nM JA treatment resulted in about $2 \%$ decrease in MDA content but in other JA ( $1 \mu \mathrm{M}$ and $1 \mathrm{pM})$ treatments $0.8 \%$ to $1.86 \%$ increase in MDA content was noticed. Enhancement of MDA content subjected to 24, 100 and $250 \mu \mathrm{M}$ JA was noticed in peanut seedlings [21] and in Scenedesmus incrassatulus [22]. Drought stress increased membrane leakage in Ocimum basilicum L. [14]. JA application protects membranes from damage by various stress factors by reducing MDA content [23]. From present study it was observed that this protection of cell membrane by
JA is very much dose dependent along with absence or presence of any stress factor such as copper in present case.

Proline is an amino acid which starts accumulating in higher amount in plants under inadequate environmental conditions which can be taken as stress marker as well as it helped the plant in protecting from harmful effect of stress. Presence of $5 \mathrm{mM} \mathrm{Cu}^{2+}$ Figure 1(d) in seedlings growth environment enhanced proline content upto $430 \%$ as compared to control (untreated distilled water). On the other hand the promoting effect of $\mathrm{Cu}^{2+}$ on proline content stimulation was lowered in presence of JA which decreased with decrease in JA concentration. These results showed that in contrast to JA, the $\mathrm{Cu}^{2+}$ stimulatory effect on proline content was sustainable and that for the neutralization of its effect higher concentration of JA was needed. JA application can promote the biosynthesis of proline and putrascine under environmental stresses [24, 25]. 1 nM JA was most effective in proline accumulation in which about $154 \%$ of more proline accumulated as compared to untreated control distilled water seedlings. These results are in accordance with Walters [26] and Seo [27].

\subsection{Superoxide Dismutase (SOD) and Peroxidase (POD) Activity}

Exogenous application of JA resultedto disturbances in the primary metabolic activities specifically photosynthetic efficiency [28] which results in an increase in the reactive oxygen species. To mitigate excess ROS generate asa consequence of JA application in presence or ab- 
sence of abiotic and biotic factors ameliorate plant antioxidant defence system which involved various enzymatic activities like superoxide dismutase (SOD) and guaiacol peroxidase (POD). SOD is an enzyme which catalyses the disproportion of superoxide radical to hydrogen peroxide and dioxygen. The increase in activity of SOD to many folds in JA treated seedlings (Figure 1(e)) of pigeonpea revealed its involvement in plant tolerance to oxidative stress caused under abiotic and biotic stresses. The present study first time revealed in that exogenous JA application increases SOD activity to many folds which help the plant in upgrading its antioxidant capacity to scavenge more free radicles. Under $\mathrm{Cu}^{2+}$ alone SOD activity increased to 2 folds as compared to control distilled water seedlings but his increase in SOD was 2 - 4 times more in seedlings but this increase in SOD was $2-4$ times more in seedling shaving JA treatment before exposing to copper. However SOD's were responded differentially to JA concentrations which may be due to different isoforms of SOD available in plant which differ in their biochemical properties as well as their developmental specificities.

The peroxidases (POD) are associated with biochemical and physiological process such as growth, cell formation, fruit development, ethylene biosynthesis as well as the response to various stresses [29]. 50 percent increase in POD activity shown in Figure 1(f) in seedling having $1 \mathrm{nM}$ JA application confirmed involvement of POD in physiological processes of growing seedlings. However, increase in JA treatment to $1 \mu \mathrm{M}$, decrease POD activity revealed again the specificity of POD to concentration of JA treatments.

\subsection{Protein Content}

Exogenous application of JA provokes accumulation of protein content (Figure 1(g)) as high as $83 \%$ more in 1 nM JA treated seedlings as compared to untreated control seedlings. JA application provoke alterations in protein content resulted in several quantitative changes in polypeptide profiles. JA reported to induce accumulation of a specific set of proteins, the so called jasmonate induced stress proteins (JISP) in rice seedlings [30]. JA induced changes in protein pattern in peanut seedlings in very dose dependent and specificity manner [21].

\section{Conclusion}

In conclusion, the exposure of pigeonpea seeds to JA resulted in protein accumulation along with enhancement of light capturing capacity by more accumulation of total chlorophyll and carotenoids under normal environment but also in presence of $5 \mathrm{mM} \mathrm{Cu}{ }^{2+}$ solution and thus found that it neutralizes the diminishing effect of $\mathrm{Cu}^{2+}$ on seedling growth. These results also indicate the role of JA in plant self defence mechanism which involved accumulation of osmolyte proline and antioxidant enzymes SOD and POD and contributes to investigation of JA role in pigeon pea plants under normal and inadequate growth conditions.

\section{Acknowledgements}

Authors are highly acknowledgedto Head, Department of Botany, Punjabi University Patiala for providing experimental facility and Head, Plant Breeding and Genetics, Punjab Agriculture University, Ludhiana for providing certified seeds of pigeonpea.

\section{REFERENCES}

[1] Y. He, H. Fukushige, D. F. Hildebrand and S. Gan, "Evidence Supporting a Role of Jasmonic Acid in Arabidopsis Leaf Senescence," Plant Physiology, Vol. 128, No. 3, 2002, pp. 876-884. doi:10.1104/pp.010843

[2] R. A. Weidhase, J. Lehmann, H. Kramell, G. Sembdner and B. Partier, "Degradation of Ribulose-1, 5-Biphosphate Carboxylase and Chlorophyll in Senescing Barley Leaf Segments Triggered by Jasmonic Acid Methylester, and Counteraction by Cytokinin," Physiologia Plantarum, Vol. 69, No. 1, 1987, pp. 161-166. doi:10.1111/j.1399-3054.1987.tb01961.x

[3] C. Wasternack and B. Hause, "Jasmonates and Octadecanoids: Signals in Plant Stress Responses and Development," Progress in Nucleic Acid Research and Molecular Biology, Vol. 72, 2002, pp. 165-221. doi:10.1016/S0079-6603(02)72070-9

[4] E. D. Ananiev, K. Ananieva, and I. Todorov, "Effect of Methyl Ester of Jasmonic Acid, Abscisic Acid and Benzyladenine on Chlorophyll Synthesis in Excised Cotyledons of Cucurbita pepo (Zucchini)," Bulgarian Journal of Plant Physiology, Vol. 30, 2004, pp. 51-63.

[5] R. Dhankar and R. Solanki, "Effect of Copper and Zinc Toxicity on Physiological and Biochemical Parameters in Vigna mungo (L.) Hepper," International Journal of Pharma and Bio Science, Vol. 2, No. 2, 2011, p. 553.

[6] A. Nicholls and M. Tarun, "Effects of Lead and Copper Exposure on Growth of an Invasive Weed, Lythrum salicaria L. (Purple Loosestrife)," The Ohio Journal of Science, Vol. 103, No. 5, 2003, pp. 129-133.

[7] V. Agrawal and K. Sharma, "Phytotoxic Effects of $\mathrm{Cu}$, $\mathrm{Zn}, \mathrm{Cd}$ and $\mathrm{Pb}$ on in Vitro Regeneration and Concomitant Protein Changes in Holarrhena antidysenterica," Biologia Plantarum, Vol. 50, No. 2, 2006, pp. 307-310. doi:10.1007/s10535-006-0027-Z

[8] H. K. Lichtenthaler, "Chlorophylls and Carotenoids: Pigments of Photosynthetic Biomembranes," In: L. Packer and R. Douce, Eds., Methods in Enzymology, Vol. 148, Academic Press, New York, 1987, pp. 350-382.

[9] R. L. Heath and L. Packer, "Photoperoxidation in Isolated Chloroplast. 1. Kinetics and Stoichiometry of Fatty Acid 
Peroxidation," Archives of Biochemistry and Biophysics, Vol. 125, No. 1, 1968, pp. 189-198. doi:10.1016/0003-9861(68)90654-1

[10] L. S. Bates, R. P. Waldren and I. D. Teare, "Rapid Determination of Free Proline for Water Stress Studies," Plant and Soil, Vol. 39, No. 1, 1973, pp. 205-208. doi:10.1007/BF00018060

[11] H. Lowry, N. J. Rosebrough, A. L. Farr and R. J. Randall, "Protein Estimation with Folin-Phenol Reagent," Journal of Biological Chemistry, Vol. 193, 1951, p. 265.

[12] Y. Kono, "Generation of Superoxide Radical during Autoxidation of Hydroxylamine and an Assay for Superoxide Dismutase," Archives of Biochemistry and Biophysics, Vol. 186, No. 1, 1978, pp. 189-195. doi:10.1016/0003-9861(78)90479-4

[13] J. Putter, "Peroxidase," In: H. U. Bergmeyer, Ed., Methods of Enzymatic Analysis, Verlag Chemie, Weinhan, 1974, pp. 685-690.

[14] M. E. Sorial and A. A. Gendy, "Response of Sweet Basil to Jasmonic Acid Application in Relation to Different Water Supplies," Bioscience Research, Vol. 7, No. 1, 2010, pp. 39-47.

[15] S. I. Beale, " $\delta$-Aminolevulinic Acid in Plants: Its Biosynthesis, Regulation and Role in Plastid Development," Annual Review of Plant Physiology, Vol. 29, 1978, pp. 95-120. doi:10.1146/annurev.pp.29.060178.000523

[16] M. Kovac and M. Ravnikar, "The Effect of Jasmonic Acid on the Photosynthetic Pigments of Potato Plant Grown in Vitro," Plant Sciences, Vol. 103, No. 1, 1994, pp. 11-17. doi:10.1016/0168-9452(94)03974-7

[17] R. A. Fletcher and D. McCullagh, "Benzyladenine as a Regulator of Chlorophyll Synthesis in Cucumber Cotyledons," Canadian Journal of Botany, Vol. 49, No. 12, 1971, pp. 2197-2201. doi:10.1139/b71-307

[18] R. Lew and H. Tsuji, "Effect of Benzyladenine Treatment Duration on D-Aminolevulinic Acid Accumulation in the Dark, Chlorophyll Lag Phase Abolition, and Long Term Chlorophyll Production in Excised Cotyledons of Dark Grown Seedlings," Plant Physiology, Vol. 69, No. 3, 1982, pp. 663-667. doi:10.1104/pp.69.3.663

[19] C. Reiss and S. I. Beale, "External Calcium Requirements for Light Induction of Chlorophyll Accumulation and Its Enhancement by Red Light and Cytokinin Pre-Treatment in Excised Etiolated Cucumber Cotyledons," Planta, Vol. 196, No. 4, 1995, pp. 635-641. doi:10.1007/BF01106754

[20] M. Orozco-Cardenas and C. A. Ryan, "Hydrogen Peroxide Is Generated Systemically in Plant Leaves by Wounding and Systemin via the Octadecanoid Pathway," Proceedings of the National Academy of Sciences of the United States of America, Vol. 96, No. 11, 1999, pp. 6553-6557. doi:10.1073/pnas.96.11.6553

[21] G. J. Kumari, A. M. Reddy, S. T. Naik, S. G. Kumar, J.
Prasanthi, G. Sriranganayakulu and P. C. Reddy, "Jasmonic Acid Induced Changes in Protein Pattern, Antioxidative Enzyme Activities and Peroxidase Isozymes in Peanut Seedlings," Biologia Plantarum, Vol. 50, No. 2, 2006, pp. 219-226. doi:10.1007/s10535-006-0010-8

[22] I. S. Fedina and K. M. Benderliev, "Response of Scenedesmus incrassatulus to Salt Stress as Affected by Methyl Jasmonate," Biology of Plant, Vol. 43, No. 4, 2000, pp. 625-627. doi:10.1023/A:1002816502941

[23] H. Bandurska, A. Stroinski and K. Jan, "The Effect of Jasmonate on the Accumulation of ABA, Proline and Its Influence on Membrane Injury under Water Deficient in Two Barley Genotypes," Acta Physiologeiae Plantarum, Vol. 25, No. 3, 2003, pp. 279-285. doi:10.1007/s11738-003-0009-0

[24] C. Chen and C. Kao, "Osmotic Stress and Water Stress Have Opposite Effects on Putrascine and Proline Production in Excised Rice Leaves," Plant Growth Regulation, Vol. 13, No. 2, 1993, pp. 197-202. doi:10.1007/BF00024262

[25] X. Gao, X. Wang, Y. Lu, L. Zhang, Y. Shen, Z. Liang and D. Zhang, "Jasmonic Acid Is Involved in the Water Stress Induced Betaine Accumulation in Pear Leaves," Plant Cell and Environment, Vol. 27, No. 4, 2004, pp. 5497-5507. doi:10.1111/j.1365-3040.2004.01167.x

[26] D. Walters, T. Colwey and A. Mitchell, "Methyl Jasmonate Alters Polyamine Metabolism and Induced Systemic Protection against Powdery Infection in Barley Seedlings," Journal of Experimental Botany, Vol. 53, No. 269, 2002, pp. 747-756. doi:10.1093/jexbot/53.369.747

[27] H. S. Seo, J. T. Song, J. J. Cheong, Y. H. Lee, Y. W. Lee, I. Hwang and J. S. Lee, "Jasmonic Acid Carboxyl Methyltransferase: A Key Enzyme for Jasmonate-Regulated Plant Responses," Proceedings of the National Academy of Sciences of the United States of America, Vol. 98, No. 8, 2001, pp. 4788-4793. doi:10.1073/pnas.081557298

[28] S. Reinbothe, C. Reinbothe, C. Heintzen, C. Seidenbecher, and B. Parthier, "A Methyl Jasmonate-Induced Shift in the Length of the 5' Untranslated Region Impairs Translation of the Plastid Rbcl Transcript in Barley," The EMBO Journal, Vol. 12, No. 4, 1993, pp. 1505-1512.

[29] M. A. Matamoros, D. A. Dalton, J. Ramos, M. R. Clemente, M. C. Rubio and M. Becana, "Biochemistry and Molecular Biology of Antioxidants in the RhizobiaLegume Symbiosis," Plant Physiology, Vol. 133, No. 2, 2003, pp. 499-509. doi:10.1104/pp.103.025619

[30] R. Rakwal and S. Komatsu, "Jasmonic Acid-Induced Necrosis and Drastic Decreases in Ribulose 1,5-Bisphosphate Carboxylase/Oxygenase in Rice Seedlings under Light Involves Reactive Oxygen Species," Journal of Plant Physiology, Vol. 158, No. 6, 2001, pp. 679-688. doi:10.1078/0176-1617-00372 